\title{
UNA CARTA MORISCA DE DOTE Y ARRAS. GRANADA (1540) Y JUAN MARTÍNEZ RUIZ
}

\author{
Joaquina Albarracín Navarro*
}

Entre los documentos inéditos que Juan Martínez Ruiz guardaba en una carpeta titulada "en elaboración", aparece transcrita una carta morisca de dote y arras escrita en letra procesal encadenada de muy difícil lectura, fechada "a treze días del mes de Nobienbre de 1540", procedente del Archivo de Notarías de Granada.

Los contrayentes son: Lorenço Hernández Abenhabid y Guiomar Axaa, de "la collaçión de S. Salbador" (Albaicín).

Primero irá una relación de la indumentaria, joyas, preseas de la casa y bienes rústicos que aparecen en el manuscrito en estudio, después cada una de las piezas enumeradas se irán completando con el material estudiado por Juan Martínez Ruiz ${ }^{1}$ que aparece en varias publicaciones; a continuación el que ofrece María Arcas Campoy ${ }^{2}$ y, finalmente, se completa la enumeración

* Universidad de Granada

1. Juan MarTíneZ Rutz. Léx. «Léxico granadino del siglo XVI», Revista de Dialectología y Tradiciones Populares (1962), 136-192. Léx. O. «Léxico de origen árabe en documentos granadinos del siglo XVI», Revista de Filologia Española XLVIII, 1965 (1966), 121-133. Inv. Inventario de bienes moriscos del Reino de Granada (siglo XVI) Linguistica y civilización. CSIC, Instituto "Miguel de Cervantes", Departamento de Dialectología y Tradiciones Populares, Madrid, 1972, 308 pp. y 20 ilustraciones. siete. «Siete cartas de dote y arras del Archivo de la Alhambra», Revista de Dialectología y Tradiciones Populares, XXII (1966). Ind. «La indumentaria de los moriscos según Pérez de Hita y los documentos de la Alhambra", Cuadernos de la Alhambra 3 (1967), 55-124. Doc. «Documentos granadinos del siglo XVI (moriscos) y léxico andaluz», I Congreso de Andalucía, diciembre 1976, Actas. III Córdoba (1978), 199-204. Ad. "Adiciones DCELC de COROMINAS", Scritti linguistici in onore di Giovan Battista PELLEGRINI, Pisa (1983), 119-133. Rop. "Ropas y ajuar de mudéjares granadinos (1493)», Revista de Dialectología y Tradiciones Populares XXXVIII(1983), 119-134). Joy. "Joyas y ropas de moriscos granadinos en un proceso inquisitorial (años 1577-1580)». Homenaje a Concepción CASADO Lobato, Revista de Dialectología y Tradiciones Populares, XLIII, Madrid (1988), 387-395.

2. Emig. María ARCAS CAMPOY, «Inventario de bienes de una morisca granadina emigrada a Lorca (Murcia)», Al-Masāq, 4 (1991), 35-49. 
con otros trabajos que he publicado sobre este tema ${ }^{3}$. De esta forma, se ampliará y perfilará cada objeto, e incluso se logre, en algunos casos, la representación gráfica tan escasa cuando se refiere a este tema en concreto. Esta norma ya la he seguido recientemente y pienso continuar, hasta formar un glosario o, si el material es abundante, formar incluso un pequeño diccionario con la mayor cantidad de material gráfico apoyándome en la Maurofilia.

ABDUL. Un abdul de çinco borlas de seda de grana con su aljófar e oro con sus trenças (fol. 1273v. 7-9). Otro abdul de seda amarilla, con colores (fol. 1273v. 10-11). Alcalá,'adul, 'cordón trenzado'. Eguílaz 'adul 'cordón o collar que usaban las moriscas de Granada, el cual se compone de trenzas de seda con labores de oro y borlas de la misma clase de color de grana, amarillo, azul y morado. Las borlas con bellotas de oro, que pendían de estos cordones o collares eran de ordinario tres, pero los había también con cinco. En vez de broche el adul se sujetaba a la garganta con botones de oro o de aljófar...' ; Inv. 41-42, adul "un adul de seda amarilla y los cabos de hilo de oro (Ugíjar-Cástaras 1562) ... un adul carmesy con oro y alxófar (Notáez) ... Ind. 101; Ad. 770. Vera. unas borlas que se diçen C; de seda $I$.

AÇEDRÍA. Una açedría que se dize bohtín. (fol. 1274r. 23) DLE 'chaleco, corpiño". Inv. 87."una açedría de seda de colores (Níjar 1553) ... una çedría colchada de colores (Granada 1562) ... una çadría de seda y algodón, rayda (Sortes 1565) ... una çadría de seda que dizen bohlin? (bohtín?), usada ... (Granada 1569) p. 99 ... una çadría amarilla, labrada de colores, de seda (Ugijar cástaras). Léx. 148; Ind. 62; Rop. 122-123. Vera. çedría B: D.

ALCOHOLERA. Una alcoholera de plata con una borla de seda grana (fol. 1275v. 2-3). Una alcoholera (fol. 1275v. 10). Inv. una alcoholera (Granada 1562); una alcoholera (Albacete de Orgiva 1565). El DLE define: "Vasija o salserilla para poner el alcohol usado como afeite por las mujeres". Del hispanoárabe k a h u l (ár. k u h l) 'antimonio, galena', esp. 'alcohol'. Vestido yebala, 74-75. El recipiente donde se guarda el antimonio se denomina en ár. tetuaní $\mathrm{m} \mathrm{k} \mathrm{o} \mathrm{h} \mathrm{l} \mathrm{a} \mathrm{'alcoholera',} \mathrm{puede} \mathrm{ser} \mathrm{de} \mathrm{cristal,} \mathrm{metal,} \mathrm{incluso} \mathrm{de} \mathrm{oro,}$ plata y marfil... se aplica el polvo de antinomio con un palillo $\mathrm{m}$ e $\mathrm{r} \mathrm{w}$ e $\mathrm{d}$ desde el lagrimal por todo el párpado a la altura del nacimiento de las pestañas, hasta el rabillo del ojo, luego se mete en la alcoholera y sirve de tapón.

ALCORÇíES v. COLLAR. Un collar con dos alcorcíes de oro.. Joy. alcorcíes ... "dos alcorcíes de oro esmaltados"... Del ár. q u r d a 'disco', 'rueda', DOZY, Gloss., 94; Eguílaz, 142 alcoçí "lisonjas o piezas de oro, con esmaltes o

3. vestido Yebala. Joaquina Albarracín NAVARRo, Vestido y adorno de la mujer musulmana de $\hat{Y}$ Yebāla (Marruecos), CSIC, Instituto de Estudios Africanos, Madrid, 1964. Vest. hisp. «El vestido y adorno hispanoárabes en el Libro de Buen Amor», Actas del I Congreso Internacional sobre el Arcipreste de Hita, Barcelona, 1973, 489-494. Vest. nov. «Vestido y adorno de la novia tetuaní», Cuadernos de la Biblioteca Espanola de Tetuán, Tetuán, junio-diciembre, 1980, 21-22, pp. 67-89. Rop. hisp. «Ropas hispano-musulmanas de la mujer tetuaní. (Marruecos)». II Jornadas de cultura islámica, "Aragón vive su historia", Teruel, 1988, 235-245. 
sin ellos, que llevaban las moriscas pendientes de sus haytes, sartales o gargantillas de aljófar". Inv. 45-46.

ALMALAFA. Una almalafa nueva de seda (fol . 1274r. 1-2) . Otra almalafa trayda (fol.1274r. 3). Inv. 48-49, 'especie de manto o velo grande con que se cubren los moros de la cabeza a los pies. Del ár. $\mathrm{m}$ i 1 h a $\mathrm{f}$ a ... una almalafa de seda, rrayda, remendada, (Granada 1562) ... una almalafa de algodón, vieja... (Granada 1562) ... una almalafa de muger, de cobijar, de algodón e lino e seda, usada (Granada 1569) ... una almalaf de algodón, de seda (Pataura) ... Ind. 81-82. Emig. 39. Almalafa ..., gran manto que cubría a las mujeres de la cabeza a los pies cuando salían a la calle y que se mantenían con la mano derecha a la altura de la nariz. Era la prenda más llamativa y, por ello, a la que se referían las prohibiciones... (70r, 38; de lienço lavrada, 70v,2). Vera. almalafa de alcotón; A; F.

ALMAYZAR. Un almayzal miriní con orillas amarillas (fol. 1275r. 27-28). Otro almayzar con orillas azules y negras (fol. 1275r. 29-30). Inv. 50 'especie de toca que generalmente se llevaba enrollada a la cabeza como un turbante', del ár. $m$ i' z a r 'especie de toca o velo' ... dos almayzares (Níjar Huebro 1562) ... dos almayçales grandes, con oro en los cabos (Nijar) ... un almayzal de fustán vareteado (Granada 1562) ... una almayzar prieto e morado, las orillas azul y colorado ... un almayzar viejo, con orillas verdes ... un almayçar de seda verde e morado (Sortes 1565) ... una almaiçar (Tabernas 1556) ... una almayçar con cabos de seda amarilla e blanca ...; Ind. 122. Vera. almayzar; dos, uno grande e otro checo, A; B; de seda, C; E; F; que se dize algaxaba marchaf, $\mathrm{G}$; un minjafo que es almayzar, $\mathrm{H}$; de lino y otro pequeño de oro, $\mathrm{I}$.

ANILLO. Tres anillos de oro, dos con turquesa y el otro con una garnata (1273v. 12-13).

AXORCA, AJORCA. Unas axorcas de oro (fol. 1273r. 17). dos axorcas de aljófar (1273v 3-4). Inv. 61-62. Del hispanoár. š u r k a 'ajorca' (del ár. šà r a k a 'lazo'), dos axorcas de oro (Nijar 1553) ... dos axorcas de aljófar, esmaltadas, con aljófar azul (1568) ... dos axorcas de plata (Sobras y Nechite 1559) ... ; Ind. 122. Vera. ajorca, axorca de oro,A; dos de oro para los braços, B; dos de oro, C, D, E, F, G, H, I. DLE 'brazalete, o sea, una especie de argolla de oro, plata $\mathrm{u}$ otro metal, que para adorno traían las mujeres en las muñecas, en los brazos o en las gargantas de los pies'4.

BALAGE v. COLLAR. Un collar ... con dos piedras balages... Joy. Balages “... ayte, con quatro balages y ..." Del ár. b a 1 a j balaj' piedra preciosa, una de las nueve especies del berilo semejante al rubí, aunque no de tan encendido color. Su nombre se relaciona con la provincia persa de Badajsān o Balajsān, de donde procede esa piedra preciosa, especie de rubí de color morado ...

4. «Nueve cartas moriscas de dote y arras de Vera (Almería)», Congreso La Frontera Oriental Nazarí como sujeto histórico (s. XIII-XVI) (en prensa). 
CAMISA. Ocho camisas de muger labradas de seda de colores (fol. 1274r. 9-10). Seys camisas labradas, la una de oro e aljófar e la otra labrada de seda blanca e las otras de seda de colores (1274r. 14-18). Inv. 76-78 ... El latín tardío CAMISIA procede del céltico THURNEYSEN, Keltorom, 52; FEF, II, 142-143). Referencias a textos medievales: Alex., Fuero de Usagre y dibujos de las Cantigas de Alfonso X, en G.LOVILLO, 48-51... (Dada la enumeración tan prolija y extensa, pondré solamente un ejemplo de las que se repiten) a) ... una camisa vieja con un pasamano (Nijar 1562) ... una camisa labrada de seda colorada y azul (Órgiva 1566) ... otra camisa de lienço casero, de red (Granada 1562) ... un pedaço de lienço, digo una camisa bordada y por coser ... b) otra camisa de honbre (Nijar 1562) ... una camisa blanca de honbre, llana (Níjar 1562) ... una camisa de honbre de lienço delgado (Granada 1562) ... ocho camisas de onbre, labradas con seda de colores e blanca, e con oro (Bubión de Poqueira 1558) ... seys camisas de honbre, de lienço delgado, labradas con seda, de blanco y negro, e la una con oro y la otra con aljófar (Granada 1569) ... una camisa de collar de oro, de lienço delgado, de onbre c) ... una camisa lavrada con redes, para muger (Nijar 1562) ... una camisa de muger, de seda, labrada de colores (Ugijar-Cástaras) ... una camisa de muger, labrada los pechos amarillos ... otras seys camisas de muger, de lienço delgado, labradas con seda de colores, de pechos a la morisca, la una por acabar (Granada 1569) ... otra camisa de muger con un cabeçón de oro y seda (Notáez 1558)... d) una camisilla pequeña de muchacho (Órgiva 1566).

CAQUAQUYBES. Unos caquaquybes (fol. 1275v. 9). Vestido Yebala. \& 24: "DOZY: Vêtements, 247), registra q a b q a b pl. q a b ā q i b y en pág. 349 registra las dos formas: $q$ u b q $\bar{a} b$ y q a b q $\bar{a}$ b y declara: "Je ne trouve cette chaussure ni au Magreb, ni dans les contrés orientales. Il semble cependant qu'on s'en servait en Espagne, car Pedro de Alcalá traduit 'çanco de palo' par q a b q a b. En Ýebā la se usa muchísimo los 'chanclos de madera' ..." Ahora podemos añadir que efectivamente las moriscas los usaban y el nombre tomado por el escribano es caquaquibes, le ha añadido el plural castellano es, lo mismo ocurre con la sílaba inicial ca, es explicable ante la dificultad que tenía el escribano al oír pronunciar el árabe y tener que transcribirlo cuando no lo conocía. Nos queda quaquib la forma correcta que he oído en Tetuán y posiblemente $\sim$ proceda del ár. dialectal granadino. No se debe olvidar que Tetuán fue repoblada en el siglo $\mathrm{XV}$ por moriscos ${ }^{5}$.

COLLAR. Un collar con dos alcorçíes de oro e con dos piedras balages y otras piedras y perlas (1273r. 24-26). Otro collar de oro, pequeño, con dos alcorcíes de oro esmaltados e perlas e aljófar, ensartados en un cordón de seda colorada (fol. 1273r. 27-30) Vestido Yebala. 88. Por la descripción puede

5. Guillermo GozAlBes Busto, Al-Mandari, el granadino, fundador de Tetuán, Granada, 1988. Id., Los moriscos en Marruecos, Granada, 1992. Hossain BouzINEB, «Los moriscos en Marruecos», II Jornadas de cultura istámica, Madrid, 1990, pp. 223-235. 
equivaler al $\mathrm{j}$ a y $\mathrm{t}$. Vera. de aljófar que se dize rexafa, $\mathrm{B}$. DLE 'adorno femenino que rodea el cuello'.

ÇABANIÍA. Una çabanía de almayzar (1275r.1). Inv. 99 dos çabanías de oro para las orejas, con sus aljófares (Granada 1569). Vestido yebala 51, aparece con el significado de 'pañuelo de cabeza' s a b a n í a, también s e b n ía.

ÇAPATO. Unos çapatos (fol. 1275v. 9). Inv. 196-197. Abundantes referencias en COROMINAS, IV, 832-836. ... dos pares de çapatos, digo un par de muger (Órgiva 1566) ... unos çapatos de onbre (Orgiva 1566) ... Emig. Calzado de hombre y de mujer. Los de la mujer podían estar ricamente confecciona dos... (70r, 27-28), Çapatos de terciopelo carmesí con franjas de oro.

ÇARAGÜELLES. Quatro pares de çaragüelles de muger (fol. 1274r. 1213). Quatro pares de çaragüelles (fol. 1274r. 1718). Inv. 197-198. (Voy a entresacar los no repetidos). Del ár. $s$ a $\mathrm{r}$ ā $w$ i 1 pl. de s i $\mathrm{r}$ wā $l$ 'pantalón muy ancho, calzoncillos'... COROMINAS IV, 840 , dice: " hoy sigue diciéndose $z a-$ ragüel en las montañas de Almería y en otras partes, empleándose mucho en singular" a) ... zaragüelles, çaragüeles ... unos zaragüeles y medias calças de paño verde (Félix 1562) ... dos pares de çaragüeles de lienço casero, con unas tiras listadas, nuevas (Granada 1562) ... quatro pares de çaragüeles largos (Nijar 1553) ... b) çaragüelles o çaragìeles de mujer: unos çaragüelles de lienço, de muger Órgiva 1566) ... unos çaragüeles de lino nuevos, de muger (Andarax) c) unos çaragüeles de honbre, de lienço, blancos (Granada 1562). d) çaragüeles de muchacho: unos çaragüeles de muchacho, de lienço (Órgiva 1566) ... Emig. 40, çaragüelos, 70r, 35, unos çaragüelos de lienço, moriscos . Vestido Yebala, 41-42, s a r wa àl o s ir wāl pl. s a rà w ì 1 .

ÇARÇILLO. Unos çarçillos de oro, de doze quentas, con su aljófar e seys pinjantes (fol. 1273r 21-23). Inv. 198-199, del latín CIRCELLUS dim. de CIRCULUS 'aro'... En Juan Ruiz çercillos 'pendientes' ... dos çarcillos de las orejas (Nijar-Huebro 1549) ... unos çarcillos de oro ...Vera. çarcillos de oro, A; de oro, F; doze çarcillos que se dizen tutes, I. DLE 'pendiente, arete'.

CORTINA. Una cortina de seda con orillas berdes (fol. 1273v 14-15). Otra cortina labrada que se dize mazhana con orillas de dos caras berde y azul (fol. 1273v. 16-18) Inv. 97 ... una cortina de seda, listado de colores (Sortes 1565) ... una cortina de seda çenin, de colores, con orillas verdes nueba, digo usada (Granada 1569).

CHAPÍN. Dos pares de chapines, los unos leonados e los otros berdes (fol. 1275v 6-7). Unos chapines valencianos (fol. 1275v. 8). Inv. 101. chapín 'calzado de mujer, con suela gruesa de corcho, de cuatro dedos o más de alto'. unos chapines e xervillas de muger, de terçiopelo verde (Granada 1562) ... unos chapines (Órgiva 1563) ...

DAMASCO. Siete baras de damasco (fol. 1275r. 26). Inv. 102. El tejido de damasco (de la ciudad de Damasco) se alude a una especie de seda. una marlota de damasco carmesí guarneçida con terçiopelo, con sus alamares de 
oro (Bubión de Poqueira). Vera. damasco de seda, H. DLE 'tela fuerte de seda o lana y con dibujos formados en el tejido'; esta tela procede de Damasco, de ahí su nombre.

ESPEJO. Un espejo de plata con una borla de seda azul (fol. 1275v. 1-2). Un espejo (fol. 1275v. 9). Inv. 106. Del lat. SPECULUM. en Berceo espejo ... un espejo, viejo, dorado (Granada 1562) ... un espejo de cristal (Granada 1569).

FOSTUL. Un fostul amarillo, con orillas de oro (fol. 1275r. 31-32). Inv. 112 festul, fustul y fostul se pueden relacionar con la forma fustal de P. Alcalá, que COROMINAS, II, 599, relaciona con el ár. de España y Argelia fustan ... dos festules de seda blanca (Nijar-Huebro 1549) ... un festul de grana y oro (Nijar 1562) ... un fustul con su oro (Tabernas 1556) ... un fustul colorado con cabos de oro (Pataura) ... un fostul de seda amarilla (Granada 1562). Emig. 39, Fostul (70r. 25), de terciopelo verde. Vera. fostul fostol de oro con sus cabos, A; pequeño, blanco, de seda y otro de seda, $C$; de seda, otro con cabos de oro, G; de seda, $H$.

GARNATA. v. anillo.

HAZERUELOS. Dos hazezuelos de zarzahán e dos hazezuelos labrados y otros dos de çanefas (fol. 1274v. 13-15. Inv. 5354, COROMINAS, i, 56, señala que almohada sustituyó al equivalente haceruelo (de haz 'cara'); todavía encontramos en estos inventarios moriscos "dos Hacericos castellanos..." (Granada 1569).

MARLOTA. Una marlota de grana e morado, con un cabeçón labrado de oro (fol. 1274r. 19-20). Inv. En P. Alcalá, ár. m u 11 u t a: "saya de mujer; vestidura de mujer; cogulla de hábito de fraile; monjil, vestidura de monje". Aparece en escrituras árabes de Granada y Almería, y en el ár. africano y asiático, ya por el s. XIII (DOZY, Dict. des Noms de Vêtements, 87, 412 ...) procede del griego con el significado de 'manto velloso. (Dada la extensa enumeración, suprimiré las repeticiones). a) marlota: una marlota de açul y verde, guarneçido de terçiopelo colorado (Albacete de Órgiva 1562) ... b) marlota de paño: una marlota de paño colorado y morado, con unos ribetillos de terçiopelo negro y unos botones de oro y alxófar (Alhambra de Granada 1566) ... otra marlota de paño verde e açul (Bubión de Poqueira 1558) ... c) marlota de terçiopelo: una marlota de tersyopelo carmesy (Nijar 1553) ... una marlota de terçiopelo de grana y verde (Tabernas 1556) ... d) marlota de damasco: una marlota de damasco morado, con una franja de oro por delante (Níjar 15533 ... e) marlota de chamelote: una marlota de chamelote, prieta, con sus ribetes de terçiopelo azul (Almería 1568) ... una marlota de chamelote negro e azul, con las bocamangas de hilo de oro e granillos de aljófar (Pataura 1559) ...f) marlota de seda: una marlota de seda con todo su adreó (Níjar-Huebro 1549). g) marlota de sarga: una marlotilla viexa de sarga (Albacete de Orgiva 1562). Vera. de terçepilo, de paño, de alcotón, A; de paño fino, B; de paño de color, fino, $C$; de paño fino, D; de seda, E; de paño, F; de paño fino, H; de terçiopelo colorado e azul, I. 
PAÑIZUELOS. Cinco panyzuelos de narizes (fol. 1274v. 31-32) Inv. 155. Como es sabido, pañizuelo deriv. de paño ya se documenta en 1355 ... quatro panyzuelos de narizes, labrados (Almería 1568) ... un panizuelo de rima, labrado de seda de colores, que no está acabado de labrar (Sortes 1568) ... dos panizuelos con rapaçelos, el uno roto, (Albacete de Órgiva 1565) ...

PEYNE. Un peyne (fol. 1275v. 10).

PLAMA. v. redlas.

POLOTE. Un polote de chamelote blanco e leonado... aforrado en lienço blanco (fol. 1274r. 21-22). Inv. pelote, polote, polot. El Dicc. define "Pellote. Vestido talar antiguo que se hacía regularmente de pieles" ... un pelote de muger, de paño plateado e canelado, usado (Granada 1569) ... un polote de paño rosado, guarnesydo con tersyopelo asul, con una franja amarilla (Nijar 1553) ... un polote de chamelote turquesado con dos fajas de terçiopelo carmesy (Granada 1562) ... Emig. Polot (70r, 25, de terciopelo verde). Vera, pelote machos de dos colores, A; de paño fino, B; çerrado, $C$; de paño, D; de seda, E; de paño fino, $F, G$.

RED. Una red de aljófar y piedras, con quatro pieças de oro que se llama nubadaf. (fol. 1273. 31-32). Inv. 167-168, una red de aljófar (Tabernas 1556) ... del ár. š a b a k a que todavía se designa en Tetuán (Marruecos) los 'trenzados de hilos de aljófar' y los 'dibujos de pespuntes a máquina' en el cuello de la camisa de la campesina š e b i $\mathrm{k}$ a dim. de š e b k a (J. Albarracín, Vestido Yebala, 21, 23 y 33). Otra referencia de bordados llamados de red una camisa lavrada con redes, para muger (Nijar 1562).

REDLAS ? Quatro redlas e una piedra que se dize plama (fol. 1273v. 5-6).

REDÍ. Un redí con orillas de manos e de diversos colores (fol. 1273v. 1920). Otro redí labrado con orillas de colores (fol. 1273v. 21-22). Inv. 168. En árabe $\mathrm{r}$ i d à 'manto'; la novia campesina de Yebala (Marruecos) usa un manto llamado r e d $\bar{a}^{\prime}$ (J. ALBARRACIN, Vestido Yebala, \& 83); en todos los documentos redí, que supone la evolución de $\bar{a}-\bar{i}$, fenómeno característico de la pronunciación árabe granadina. a) un redí (Bubión de Poqueira 1558) ... b) redí con orillas de seda de colores: un redí con orillas coloradas (Níjar 1568) ... otro redí con las orillas de seda amarilla (Sortes 1565) ... c) redí de lienço: un redí listado de lienço ... otro rredí de lienço con sus orillas de seda amarilla ... d) redi de seda: ... un rredí de seda fina de colores (Nijar 1553) ... tres rredíes de seda de todos colores, las dos con orillas verdes y la una con la orilla amarilla (Notáez). Vera. redí de seda, F.

SAYO. Un sayo de terciopelo negro (fol. 1274v. 30). Inv. 176-177. ... Según DOZY, Vêtements, las damas turcas y renegadas llevaban normalmente sobre su camisa un vestido que va hasta media pierna y que está hecho, bien de cualquier tela fina de color, bien de escarlata de Venecia, de satín, de terciopelo, de damasco, etc., estas tres últimas telas son siempre de color. Este vestido tiene el cuello muy escotado, de forma que está abierto hasta el 
pecho. A la altura de éste se encuentran algunos botones grandes de oro o de plata muy bien hechos. Ellas llaman a este vestido gonila.

TABE. Un tabe (fol. 1274r. 24). Vera. atabe del árabe i t b 'túnica sin mangas, generalmente rayada' según DOZY Vêtements.

TERCIOPELO. Quatro baras de terçiopelo calmesí 8 ds. (fol. 1275r. 2324). Quatro baras de terçíopelo azul 8 ds. (fol. 1275r. 25). Doze baras de calmesí 36 ds. (fol. 1275v. 1415). Vera. una marlota de terçepilo, A.

TOCAS. Dos tocas de seda que se dizen quina (fol. 1275r. 33-34). DLE 'Prenda de tela, generalmente delgada, de diferentes hechuras, según los tiempos y países, con que se cubría la cabeza por abrigo, comodidad o adorno. Inv. a) toca ... una toca con una orilla colorada en cada cabo (Andarax 1566) ... una toca de muger, deshilada, vieja y rota (Granada 1562) b) toca de seda ... una toca labrada de seda de colores (Sortes 1565) ... una toca de seda amarilla (Albacete de Órgiva) ... una toca de seda blanca (Pataura 1556). c) toca de lienço ... una toca de lienço gordo (Nijar 1568) ... una toca de lienço delgado con unas orillas de seda verde (Granada 1562) ... d) toca de lino ... una toca de lino, raída (Órgiva 1556) ... una toca de lino (Salobras 1559) ...e) toca de calicud. una toca de calicud (Tabernas 1556) $f$ ) toca de agache. tres tocas de azache (Nijar 1568). Emig. Toca (70r,31, jaspeada, con aljófar). Prenda a modo de sombrero o turbante.

TURQUESA. v. anillo.

XERBILLAS. Dos pares de xerbillas de terçiopelo, las unas de carmesí, las otras dos de azul (fol. 1275v. 4-5). Inv. xerbilla 195. Probablemente del lat. SERViLiA SANDALIA 'sandalias de esclavos', según COVARRUBIAS y SIMONET, 591. se documenta serbilla en principios del XV ... en el ár. marr. še r b i 1 pl. ša rāb i l, Vestido Yebala, \& 20, p. 55 ...) ... unos chapines e xerbillas de muger, de terçiopelo verde (Granada 1562).

HECHURA. (confección) La hechura de una marlota de seda grana e azul y otra hechura de otra marlota de damasco morado y negro, apreçiadas laS hechuras en 8 ducados (fol. 1274r. 25 28).

\section{PRESEAS DE CASA.}

Presea. ant. //Mueble y utensilio que sirve para el uso y comodidad de las casas//.

ALHONBRA. Una alhonbra en 8 ds. (fol. 1274v. 21). Otra [alhonbra] de Berbería 5 ds. (fol. 1274v. 22). Inv. Del ár. j ū m r a anteponiendo el artículo al, 'alfombra' ... una alhombra (Níjar 1562) ... una aljonbra de listas, de seda amarilla y de lino delgado (Níjar 1553) ... una alhonbra (Tabernas 1566).

ALMIRÉS. Un almirés e una baçina de açófar 15 rs. (fol. 1275r. 7-8). Inv. 50. Del ár. $\mathrm{m}$ i h r à s, nombre de instrumento, 'mortero, almirez' .... un almirez de metal con su mano, chico (Granada 1562) ... un almirez de fuslera con su mano (Granada 1569). 
ALMOHADA. Quatro almohadas grandes que se llaman megnedez 15 ds. (fol. 1274v. 3-4). Seys almohadas de zarzahán, 8 ds. otras seys almohadas labradas de seda toda la cara, 14 ds. (fol.1274v. 7-8). Otras tres almohadas labradas de çanefas. 4 ds. (fol. 1274v 9-10). Otras seys almohadas de fustán 3 ds. (fol. $1274 \mathrm{v}$. 11-12). Otras quatro almohadas labradas a la castellana, las dos labradas de seda negra, e las dos de seda grana 6 ds.(fol. 1274v. 16-19). Dos almohadas de paño $1 \mathrm{~d}$. (fol. 1274v. 20). Inv. 51-54. del ár. $\mathrm{m} \mathrm{i} \mathrm{j} \mathrm{a} \mathrm{d} \mathrm{d} \mathrm{a,}$ nombre de instrumento derivado de $\mathrm{j}$ a $\mathrm{d} d \mathrm{~d}$ 'mejilla' (vid. hazeruelo) ... otra almoada lavrada de seda (Ní jar 1568 ) ... diez y ocho almohadas de colores, las çinco llenas de lana (Ugíjar 1562) ... quatro almohadas de cara (Nijar 1562) ... una almohada de lienço listado (Almería 1568) ...

BAÇINA. v. Almirés. Inv. 64. Derivado de baçin y éste del latín tardío BACCHINON 'orinal'. una baçina de latón mediana (Granada 1562).

CABEÇA. Dos cabeças de cama labradas con sus çanefas, con borlas de seda amarilla 5 ds. (fol. 1274v. 23-25). Inv. 70.

COLCHA. Una colcha de paño de colores, con la açanefa de hilado amarillo 10 ds. (fol. 1274v 1-2). Inv. 93. Sabido es que colcha designó primitivamente ' colchón para echarse o sentarse en el suelo', del pr. ant. colche 'yáciga, lecho' ... El significado 'cobertura gruesa de cama' es el de los inventarios moriscos. ... dos colchas moriscas (Alhambra de Granada 1566) ... una colcha morisca con el envés de lienço azul (Granada 1562).

COLCHÓN. Quatro colchones con las caras de algodón, malequíes 12 ds. (fol. 1274v. 26-27). Inv. Derivado de colcha ... a) colchón, sin indicar el contenido: ... ocho colchones de cara de colores (Níjar-Huebro 1549) ... b) colchón, lleno de lana: ... tres colchones moriscos llenos de lana (Granada 1572) ... ocho colchones, los tres con lana (Tabernas 1556) ... c) colchón lleno de tascos: otro colchón listado, lleno de tascos (Granada 1562) ... dos colchones llenos de tascos (Adra 1568) ...

GUADAMEÇIL. Dos guadameçiles matrahes de cordobán 9 rs. (fol. 1274v. 28-29). Inv. 118 guadameçí ... Como es sabido guadamecí 'cuero adobado y adornado con dibujos de pintura o relieve' del ár. $\hat{y} \mathrm{i} l \mathrm{l}$ g a d ã m a s i 'cuero de Gadámes'. Ciudad de Tripolitania donde se preparaba este famoso artículo ... un almadraque de guadameçí y el envés de lienço azul lleno de tascos (Granada 1562 ) ... tres coxines de guadameçil dorado, pequeños (Granada 1562) ...

\section{BIENES RÚSTICOS}

Una haça de tierras de riego, de 10 marjales, poco más o menos, en Purchil, alinde de haça del Zenín e alinde de tierras de los habizes y el açequia, apreçiada en 45 ds. (fol. 1275r. 2-6).

Esta relación de indumentaria, joyas, preseas de casa y bienes rústicos que se han enriquecido con el material de otros trabajos sobre el mismo 
tema, que nos amplía el horizonte para el conocimiento e incluso dan nuevas noticias sobre lo ya conocido, por lo tanto, cada nueva aportación nos ayudará a conseguir, por fin, una representación gráfica de cualquier prenda o joya que todavía no se ha definido lo suficiente en los documentos consultados. En trabajos posteriores se irán estudiando las nuevas aportaciones que nos proporciona la carta morisca granadina, objeto de esta comunicación, ya que ahora se sobrepasaría el límite propuesto.

Menéndez Pidal ${ }^{6}$ y también coincide Carmen Bernis ${ }^{7}$ nos orientan para que busquemos la representación gráfica en la Maurofilia, que surgió en la sociedad castellana de la época, al admitir muchos elementos de la moda del mundo islámico y utilizarla como propia. Sabemos que el Islam admite la representación gráfica en textos literarios y científicos, pero si los revisamos aparecerán personajes a los que se puede ver solamente la indumentaria exterior. Por lo tanto ¿cuáles y cómo eran los vestidos, por ejemplo, que los castellanos tomaron de los musulmanes de Al-Andalus? Una gran ayuda para contestar a esta pregunta la tenemos al revisar la escultura y todavía más, la pintura de las iglesias, catedrales, monasterios, colecciones particulares y museos como ya ha hecho, con gran acierto, Carmen Bernis a lo largo de su excelente obra, pero todavía queda mucho material por revisar, para llegar, como decía anteriormente, a tener una visión más profunda y completa. El resultado de lo que se va estudiando lo podemos comprobar en el MINJAFO, es un almayzar tejido con tela de toalla, del ár. $\mathrm{m}$ i n š a f a 'toalla' que gracias a una ilustración recogida por Carmen Bernis, se ha podido comprobar la forma de plegarlo alrededor de la cabeza, aunque todavía no se conozca el grosor del tejido.

Por otro lado, nos encontramos con nombres imposibles de localizar por ahora, deben esperar a que otro documento nos dé más noticias. Hay que seguir por este camino, un poco árido, pero con mucha paciencia y entusiasmo producidos por el interés en estos temas, se logrará.

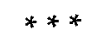

6. Ramón Menéndez Pidal, España y su Historia, Madrid, Minotauro, 1957, vol. II, pp. 276.

7. Carmen BERNIS, «Modas moriscas en la sociedad cristiana española del siglo XV y principios del XVI», Boletín de la Real Academia de la Historia, CXLIV, Madrid, 1959, pp. 199-228. 


\section{APÉNDICE DOCUMENTAL}

Protocolo, Granada, 1539-1541

Notaría de:

Luis de Ribera

Alonso de Rueda

ALonso de Herrera

Tomo único

(fol. 1273r)

${ }^{1}$ Sepan cuantos esta carta de dote e arras vieren, ${ }^{2}$ como yo Lorenço Hernández Abenhabid, hijo de ${ }^{3}$ Alonso Gonçález e María Jabalía, mis señores e padre $\mathrm{e}^{4}$ madre, veçino que soy d'esta nonbrada e grand çibdad de Granada, ${ }^{5}$ colaçión de San Miguel, digo que por quanto yo soy desposado ${ }^{6}$ por palabras de presente hazientes matrimonio con vos, doña ${ }^{7}$ Guiomar Axaa, hija de Alonso el Axa e Ysabel Tautía, vecinos ${ }^{8}$ de esta dicha çibdad, en la colaçión de San Salbador e por ${ }^{9}$ quel yo me quiero belar con vos, la dicha mi esposa, e reçibir ${ }^{10}$ las bendiçiones de la Santa Madre Yglesia, otorgo e ${ }^{11}$ conduzco que resibo en dote e casamiento con vos la dicha doña ${ }^{12}$ Guiomar mi esposa, de los dichos Alonso el Axa e Ysabel Ta- ${ }^{13}$ utía, buestros padre e madre, los bienes e axuar e joyas siguien- ${ }^{14}$ tes apreçiados por Gonçalo Hernández Mondéjar e Hernando el ${ }^{15}$ Jabalí, mercaderes vecinos d'esta dicha çibdad de Granada, en la ma- ${ }^{16}$ nera siguiente:

17 Primeramente dos axorcas de oro ${ }^{18}$ apreciadas en treynta ducados que son $\mathrm{e}^{19}$ montan honze mill e dozientos e çinquenta ${ }^{20}$ maravedís.

${ }^{21}$ Unos çarçillos de oro,de doze quentas, con $^{22}$ su aljófar e seys pinxantes, en tre- ${ }^{23}$ ynta e dos ducados.

${ }^{24}$ Un collar con dos alcorcíes de oro e con dos pie- ${ }^{25}$ dras balages y otras piedras y perlas ${ }^{26}$, apreçiado en treynta ducados.

${ }^{27}$ Otro collar de oro, pequeño,con dos alcor- ${ }^{28}$ çíes de oro, esmaltados. e perlas $\mathrm{e}^{29}$ aljófar, ensartados en un cordón de ${ }^{30}$ seda colorada, en ocho ducados. ${ }^{31}$ Una red de aljófar y piedras, con quatro pieças ${ }^{32}$ de oro,que se llaman badaf, e un collarico de

(fol. $1273 v)^{1}$ oro con veynte y ocho pieças, en treynta ${ }^{2}$ ducados.

Dos axorcas de aljófar, que son dos, apre- ${ }^{4}$ çiadas en çinco ducados.

${ }^{5}$ Quatro redlas? e una piedra que se dize pla-6 ma y otra azul, en quatro ducados.

${ }^{7}$ Un abdul de çinco boorlas de seda de grana ${ }^{8}$, con su aljófar e oro,con sus tren $-{ }^{9}$ ças, en tres mill maravedís.

${ }^{10}$ Otro abdul de seda amarilla, con colores, ${ }^{11}$ en dos ducados ${ }^{12}$ Tres anillos de oro, los dos con turquesas, $\mathrm{e}^{13}$ otro con una garnata, en dos ducados y medio.

${ }^{14}$ Una cortina de seda, con orillas berdes a- ${ }^{15}$ preçiada en beynte ducados.

${ }^{16}$ Otra cortina de seda labrada,que se dize ${ }^{17}$ mazhana,con orillas de dos $\operatorname{caras}^{18}$, berde y azul, en veynte ducados. 
${ }^{19}$ Un redí con orillas de manos e de diver- ${ }^{20}$ sas colores, en catorze ducados.

${ }^{21}$ Otro redí labrado con orillas ama-22 rillas, raído, en ocho ducados.

${ }^{23}$ Una sábana labrada, con orillas de ${ }^{24}$ colores, en seys ducados.

${ }^{25}$ Dos paños de manos, el uno labrado con ${ }^{26}$ orillas, y el otro blanco, con orillas, ${ }^{27}$ en quatro ducados.

${ }^{28}$ Otros dos paños de manos con orillas ${ }^{29}$ amarillas e con bibos de seda, en ${ }^{30}$ tres ducados.

${ }^{31}$ Otros dos paños de manos, labrados de seda ${ }^{32}$ de grana, con sus trenças alde ${ }^{32}$ rredor, en quatro ducados.

(fol. 1274r)

${ }^{1}$ Una almalafa nueva, de seda, apreçiada en ${ }^{2}$ doze ducados. ${ }^{3}$ Otra almalafa trayda, en quatro ducados.

${ }^{4}$ Dos sábanas labradas, en seys ducados.

${ }^{5}$ Otras dos sábanas, con orillas azules, en ${ }^{6}$ dos ducados. ${ }^{7}$ Dos paños de manos labrados e con orillas, ${ }^{8}$ apreçiados todos en tres ducados.

${ }^{9}$ Ocho camisas de muger labradas de se ${ }^{10}$ das de colores, apreçiadas en seys mill ${ }^{11}$ maravedís.

${ }^{12}$ Quatro pares de \$aragueles de mujer, en qua- ${ }^{13}$ troçientos e ochenta maravedís.

${ }^{14}$ Seys camisas labradas /6, la una de oro e ${ }^{15}$ aljofar, e la otra labrada de seda ${ }^{16}$ blanca e las otras de seda de colores con ${ }^{17}$ quatro pares de çaragueles, todo en quatro ${ }^{18}$ mill e noveçientos e ochenta. dos.

${ }^{19}$ Una marlota de grana e morado, con un ca- ${ }^{20}$ beçón labrado de oro,en seys duca-

${ }^{21}$ Un polote de chamelote, blanco e leonado, ${ }^{22}$ en nueve ducados, aforrado en lienço blanco.

${ }^{23}$ Una açedría que se dize bohtín, en ocho ducados.

24 Un tabe en tres ducados.

${ }^{25} \mathrm{La}$ hechura de una marlota de seda de grana ${ }^{26}$ e azul, y otra hechura de otra marlo- ${ }^{27}$ ta, de damasco morado e negro, apreçiadas ${ }^{28}$ las hechuras en ocho ducados. ducados.

${ }^{29}$ Una colcha de zarzahán, con la çenefa de ${ }^{30}$ tafetán amarillo, apreçiada en veynte ${ }^{31}$

${ }^{32}$ Otra colcha de paño de colores, con la

(fol. $1274 \mathrm{v})^{1}$ açanefa de hilado amarillo,apreçiada en diez ${ }^{2}$ ducados.

${ }^{3}$ Quatro almohadas grandes, que se llaman ${ }^{4}$ meznedez apreçiadas en quinçe ducados.

${ }^{5}$ Seys almohadas de zarzahán, en ocho ${ }^{6}$ ducados.

${ }^{7}$ Otras seys almohadas labradas de seda toda ${ }^{8}$ la cara, en catorze ducados.

${ }^{9}$ Otras tres almohadas labradas de ça- ${ }^{10}$ nefas, en quatro ducados e medio.

${ }^{11}$ Otras seys almohadas de fustán, ${ }^{12}$ en tres ducados.

${ }^{13}$ Dos hazeruelos de zarzahán e dos ha- ${ }^{14}$ zeruelos labrados y otros dos de çanefas, ${ }^{15}$ en tres ducados.

${ }^{16}$ Otras quatro almohadas labradas a ${ }^{17}$ la castellana, las dos labradas de se- ${ }^{18} \mathrm{da}$ negra,e las dos de seda de grana, en ${ }^{19}$ seys ducados. 
${ }^{20}$ Dos almohadas de paño, en un ducado.

${ }^{21}$ Una alhonbra en ocho ducados.

${ }^{22}$ Otra de berbería, en çinco ducados.

${ }^{23}$ Dos cabeças de cama labradas, con sus ${ }^{24}$ çanefas con borlas de seda amarilla, en ${ }^{25}$ çinco ducados.

${ }^{26}$ Quatro colchones con las caras de algodón, ${ }^{27}$ malaquíes, en doze ducados.

${ }^{28}$ Dos guadameSiles matrahes de cordobán, ${ }^{29}$ en nueve reales.

${ }^{30}$ Un sayo de terçiopelo negro,nuebe ducados.

${ }^{31}$ çinco pañizuelos de narizes, en un duca- ${ }^{32} \mathrm{do}$.

(fol. 1275r)

${ }^{1}$ Una çabanía de almayzar, en un ducado.

${ }^{2}$ Una haça de tierras de riego, de diez mar $-^{3}$ jales, poco más o menos, en Purchil, alinde ${ }^{4}$ de haça del Zenín e alinde de tierras de ${ }^{5}$ los habizes y el açequia, apreçiada en qua ${ }^{6}$ renta e çinco ducados.

${ }^{7}$ Un almirés e una baçina de açófar,en quinze ${ }^{8}$ reales.

${ }^{9}$ Por manera que suman e montan los maravedís e joyas e axuar $\mathrm{e}^{10}$ preseas de casa susodichas, apreçiadas en la manera que dicho es, ${ }^{11}$ çiento e ochenta e quatro mill e quatroçientos e sesenta ${ }^{12}$ e nueve maravedís e medio de la moneda usual, de las quales ${ }^{13} \mathrm{di}^{-}$ chas joyas e preseas de casa me doy y otorgo por bien con- $-^{14}$ tento y entregado toda mi voluntad por quanto las re ${ }^{15}$ çibí en presençia del escrivano público e testigos d'esta del a- ${ }^{16}$ quel entregamiento, yo el presente escrivano publico, doy fee que pasó ${ }^{17}$ e se hizo en mi presençia e de los dichos testigos,en las dichas ${ }^{18}$ joyas e axuar e otrosí otorgo e conduzco yo el dicho ${ }^{19}$ Lorenço Hernández Abenhabid, que mando e doy en a- ${ }^{20}$ rras e donaçión a vos, la dicha mi esposa por $^{21}$ honra de vuestra virginidad los bienes e joyas ${ }^{22}$ siguientes:

${ }^{23}$ Quatro baras de terçiopelo calmesí, en ocho ${ }^{24}$ ducados. ${ }^{25}$ Quatro baras de terçiopelo azul en ocho ducados.

${ }^{26}$ Siete baras de damasco, en siete ducados.

${ }^{27}$ Un almayzal miriní con orillas ama- ${ }^{28}$ rillas, en tres ducados.

${ }^{29}$ Otro almayzar con orillas azules ${ }^{30}$ y negras, en dos ducados.

${ }^{31}$ Un fostul amarillo, con orillas de oro, en ${ }^{32}$ dos ducados.

${ }^{33}$ Dos tocas de seda, que se dizen quina $\mathrm{en}^{34}$ quinze reales.

(fol. 1275v)

${ }^{1}$ Un espejo de plata con una borla de seda ${ }^{2}$ azul, e una alcoholera de plata con una ${ }^{3}$ borla de seda de grana, en honze ducados.

${ }^{4}$ Dos pares de xerbillas de terçiopelo, las ${ }^{5}$ unas de carmesí e las otras de azul, e dos ${ }^{6}$ pares de chapines, los unos leonados, e $\operatorname{los}^{7}$ otros berdes, en seys ducados.

${ }^{8}$ Unos chapines valençianos e unos çapa- ${ }^{9}$ tos e unos caquaquybes e un espejo $\mathrm{e}^{10}$ una alcoholera e un peyne, en mil maravedís.

${ }^{11}$ En dineros contados treynta ducados.

${ }^{12} Y$ ten que os tengo de dar para el día de ${ }^{13}$ Pascua de Navidad primera venidera, fin d'este año, doze varas de carmesí que bal ${ }^{15}$ gan treynta e seys ducados.

${ }^{16}$ Ansí que montan los maravedís e joyas que así os mandlo $e^{17}$ doy en arras, quarenta e tres mill e ochoçientos ${ }^{18}$ e ochenta e çinco maravedís de la moneda usual, los qua- 
les con- ${ }^{19}$ fieso e declaro que cabe en la déçima parte de mis bienes ${ }^{20}$, que oy día tengo e poseo, por manera que suman e montan ${ }^{21}$ los maravedís del dicho vuestro dote e arras e axuar e preseas ${ }^{22}$ de casa con los dichos quarenta e tres mill e ochoçien ${ }^{23}$ tos e ochenta $\mathrm{e}$ çinco maravedís, que ansí os mando e doy en a- ${ }^{24}$ rras dozientos e beynte e ocho mill e trezientos e çinquenta ${ }^{25}$ e quatro maravedís e medio,los quales prometo e me obligo de tener ${ }^{26}$ enhiestos e bien parados, en lo mejor de mis bienes ${ }^{27}$ muebles e rayzes. los quales prometo de no obligar ${ }^{28}$ a mis debdas çibiles ni criminales, e me obligo de acudir ${ }^{29}$ con ellas a vos, la dicha dona Guiomar Axaa, mi esposa ${ }^{30} \mathrm{e}$ a quien por vos lo obiere de aver o buestro poder obiere, cada ${ }^{31}$ e quando que el matrimonio entre bos e mí, fuere disuelto e a- partado, por muerte de qualquier de nos e por divorçio e por ${ }^{33}$ qualquier de los casos que la ley dispone que los matri-

(fol. 1275v)

${ }^{1}$ monios se disuelben e apartan. Por lo qual todo que dicho es an $-^{2}$ sí tener e guardar e cunplir e pagar e mantener ${ }^{3}$ e aver por firme obligo mi persona e bienes muebles e ray $-^{4}$ zes, avidos e por aver, e doy y otorgo poder cunplido $\mathrm{a}^{5}$ todos e qualesquier, alcaldes, juezes e justiçias de ${ }^{6}$ sus magestades qualquier fuero e juridiçión que sean, para que por $^{7}$ todo rigor de derecho me aplicaren a lo ansí cunplir e pagar ${ }^{8}$ e por aber por firme como si esta carta fuese fenida firmada $\mathrm{de}^{9}$ de juez conpetente, pasada en cosa juzgada. Sobre lo qual ${ }^{10}$ renunçio todas e qualesquier leyes e fueros e derechos que sean en mi fabor que me non balan, espeçialmente renunçio ${ }^{12}$ la ley del derecho en que diz que jeneral renunçiaçión ${ }^{13}$ fecha de leyes non bala. En testimonio de lo qual otor-14 gué esta carta ante el escrivano público e testigos de yuso ${ }^{15}$ escritos, en cuyo ...

\section{BIBLIOGRAFÍA ADICIONAL}

AlCalá. Pedro de AlCalÁ, Arte para ligeramente saber la lengua aráviga. Vocabulista arávigo en lengua castellana (Granada, 1505), edición Paul Lagarde (Göttingen, 1883).

COROMINAS. J. COROMINAS, Diccionario crítico etimológico de la lengua castellana, Madrid, 1954,4 vols.

Covarrubias. Sebastián de Covarrubias, Tesoro de la Lengua Castellana o Española, ed. preparada por Martín de Riquer, Barcelona, 1943.

DLE. Diccionario de la Lengua Española, Madrid, 1970.

Dozy. R.P.A. DozY, Dictionnaire détaillé des noms des vêtements chez les Arabes, Amsterdam, 1845.

SIMONET. Francisco J. SIMONET, Glosario de Voces Ibéricas y Latinas usadas entre los Mozárabes, Madrid, 1888. 